\title{
O ENTENDIMENTO DE PROFESSORES EXPERIENTES AO SEREM DESAFIADOS A DESENVOLVER O ENSINO DE QUÍMICA A PARTIR DE TEMAS DO CONTEXTO SOCIAL
}

\author{
LA COMPRENSIÓN DE LOS PROFESORES CON EXPERIENCIA \\ ANTE EL RETO DE DESARROLLAR LA ENSEÑANZA DE QUÍMICA \\ DESDE TEMAS DEL CONTEXTO SOCIAL.
}

\author{
Ana Luiza de Quadros (aquadros@qui.ufmg.br) \\ Departamento de Química/ICEx, Universidade Federal de Minas Gerais \\ Giovana França Carneiro Fernandes (giovanafcf@hotmail.com) \\ Departamento de Química/ICEx, Universidade Federal de Minas Gerais \\ Mariana Gonçalves Dias (marianagoncalves1 @live.com) \\ Departamento de Química/ICEx, Universidade Federal de Minas Gerais \\ Laila Thayanne Gomes de Almeida (lailatgalmeida@hotmail.com) \\ Faculdade de Educação, Universidade Federal de Minas Gerais
}

\begin{abstract}
Resumo: O ensino a partir de temas de interesse dos estudantes, que propiciem a inserção de conceitos científicos, é um pressuposto importante para promover a participação ativa dos estudantes e o envolvimento deles com a Ciência. A partir de um material didático de Química no qual os conceitos científicos foram inseridos a partir da discussão envolvendo o tema "Água", professores experientes desenvolveram um conjunto de aulas, nas escolas da Educação Básica. Com o objetivo de analisar a percepção dos professores sobre o ensino a partir de temas do contexto, desenvolvemos este trabalho. Ao final da experiência, realizamos uma entrevista semiestruturada com os três professores. Nessa entrevista os professores ressaltaram a grande participação e o interesse dos estudantes nas aulas desenvolvidas a partir de um tema do contexto e, ainda, a dificuldade de realizar aulas temáticas sem um material didático adequado, tanto para o professor quanto para os estudantes. Por se tratar de professores experientes, entendemos que esses dados trazem implicações para o campo de Ensino de Ciências.
\end{abstract}

Palavras-chave: ensino baseado no contexto; Química; material didático.

Resumen: La enseñanza desde temas de interés de los estudiantes, que propicien la inserción de conceptos científicos, es un requisito importante para promocionar la participación activa de los estudiantes y el involucramiento de ellos con la Ciencia. A partir de un material didáctico de Química en el cual se insertaron conceptos científicos desde la discusión sobre el tema "Agua", los profesores con experiencia desarrollaron un conjunto de clases en las escuelas. Con el fin de analizar las percepciones 
de los profesores sobre la enseñanza a partir de temas del contexto, desarrollamos este trabajo. Al final del experimento, realizamos una entrevista semiestructurada con tres profesores. En esta entrevista, han enfatizado la gran participación e interés de los estudiantes en las clases desarrolladas a partir de un tema del contexto y también la dificultad de realizar clases temáticas sin tener un material didáctico adecuado, tanto para el profesor como para los estudiantes. Debido a que son profesores con experiencia, creemos que estos datos pueden proporcionar implicaciones en el campo de la enseñanza de Ciencias.

Palavras claves: enseñanza basada en el contexto; Química; material didáctico.

\section{INTRODUÇÃO}

Trabalhos presentes na literatura têm enfatizado a relação direta entre o Ensino de Ciências e os pressupostos do movimento Ciência, Tecnologia e Sociedade (CTS). O ensino a partir de temas de interesse dos estudantes, que propiciem a inserção de conceitos científicos, é um pressuposto importante para promover a participação ativa dos estudantes e o envolvimento deles com a Ciência. Essa possibilidade tem sido explorada em algumas publicações (por ex. KING; RITCHIE, 2013; ULUSOY; ONEN, 2014; UMMELS et al., 2015; BROMAN; BERNHOLT; PARCHMANN, 2015; NIEZER; SILVEIRA; SAUER, 2017; RODRIGUES; QUADROS, 2019) com resultados positivos tanto em termos de envolvimento dos estudantes quanto em tornar as aulas mais dinâmicas.

Em um projeto de extensão e dois de pesquisa ${ }^{1}$ desenvolvidos na Universidade Federal de Minas Gerais (UFMG), foram produzidas sequências didáticas temáticas, com a transformação de algumas delas em material didático impresso. Formando a coleção "Temas de Estudo em Química", foram elaborados três cadernos temáticos usando a "água" como tema gerador, abordando os subtemas "Ciclo da água", "Água na natureza" e "A água e as plantas". Esse material foi desenvolvido por professores pesquisadores, tanto da área de Ensino de Química quanto da área de Química, em parceria com professores em formação, que testavam as aulas e auxiliavam na análise dos resultados junto aos estudantes, o que gerou um longo processo de formulação/reformulação das sequências didáticas. Em uma parceria com escolas da Educação Básica, esse material foi entregue a algumas turmas de estudantes para que fosse desenvolvido em sala de aula.

De Jong (2008) afirma que o sucesso do ensino a partir de temas do contexto depende de pensá-lo em três perspectivas: a formação dos professores, o currículo e os estudantes. Isso reforça o nosso entendimento de que o resultado, em termos de aprendizagem, a partir de uma sequência didática temática depende da performance do

\footnotetext{
${ }^{1} \mathrm{O}$ projeto de extensão "Práticas Motivadoras de Química para escolas públicas de Minas Gerais teve o apoio da CAPES, por meio de bolsas de iniciação a docência e para o professor da escola, durante os anos de 2011 a 2014. Em 2013 o projeto de pesquisa "Temas de Estudo em Química", apoiado pela FAPEMIG, contribuiu para a produção e análise de dados com esse material didático e, em 2015, o projeto Ciências no contexto social, também apoiado pela FAPEMIG, complementou a pesquisa envolvendo esse material.
} 
professor. Com a intenção de analisar a vivência de professores experientes ao desenvolverem aulas de Química a partir de um tema do contexto dos estudantes, desenvolvemos este trabalho. Nele, entrevistamos três professores, após terem desenvolvido as sequências didáticas, tendo o material didático impresso como apoio.

\section{REFERENCIAL TEÓRICO}

O presente trabalho explora um material didático produzido a partir de um tema do contexto e o significado desse material para um grupo de professores. Assim sendo, dividimos o referencial de forma a considerar trabalhos que investigaram o uso de materiais didáticos cujo conteúdo foi organizado considerando o contexto (2.1) e as diferentes perspectivas de contexto (2.2), explicitando a mais condizente com o nosso trabalho.

\subsection{Experiências docentes com ensino baseado no contexto social}

Walan, Nilsson e Mc Ewen (2017) investigaram dois professores primários que trabalhavam com o ensino baseado em contexto, com a intenção de relacionar as estratégias de ensino utilizadas por eles no desenvolvimento de aulas usando a água como tema gerador do conhecimento com a percepção dos professores sobre a compreensão dos estudantes e/ou dos resultados de aprendizagem pretendidos. Para isso se valeram de uma entrevista com os professores e de um questionário com os estudantes. De acordo com os dados, os pesquisadores argumentam que não houve relação entre as escolhas das estratégias e o conhecimento dos professores em relação a possíveis compreensões dos estudantes.

No trabalho de Walan e Mc Ewen (2017), as pesquisadoras acompanharam um grupo de professores que participou de uma formação continuada em que o ensino a partir do contexto dos estudantes foi um dos focos. Elas investigaram as reflexões dos professores sobre as estratégias de ensino propostas durante a etapa de formação contínua e se eles consideravam o modelo útil nas escolas primárias em que atuavam. Segundo elas, antes de participar do programa, os professores argumentavam pela importância da participação ativa dos estudantes nas atividades propostas e, após essa participação, eles construíram argumentos adicionais, principalmente relacionados ao objetivo do ensino. Com isso, as pesquisadoras consideraram uma melhora no entendimento dos professores em relação às estratégias para tornar o estudante mais ativo na sala de aula. Porém, as pesquisadoras alertam para a necessidade de investigações adicionais relativas aos objetivos do ensino baseado no contexto.

Walan, Mc Ewen e Gericke (2016), por sua vez, investigaram 12 professores de escolas primárias, para identificar os desafios que enfrentavam ao ensinar Ciências baseados no contexto e as estratégias que usavam para enfrentá-los. Para tal usaram as reflexões feitas no coletivo e os portfólios individuais. Como resultado, eles encontraram desafios relacionados à identificação de contextos adequados para a aprendizagem; à falta de tempo; ao fato de estudantes, na manipulação de materiais, trabalharem cada qual a seu tempo; e ao gerenciamento de classe. No entanto, os próprios professores apontaram soluções para o que chamaram de desafios.

Overman et al. (2014) investigaram a opinião de 480 estudantes holandeses, cujo currículo de Química havia sido reformulado para que o ensino acontecesse a partir do contexto. Com isso, eles pretendiam compreender, além da opinião dos estudantes, se os professores implementaram essa abordagem como foram orientados e se atingiram as intenções do currículo oficial, usando três perspectivas teóricas: uma de conteúdo, uma 
de atividades de aprendizagem e uma interpessoal. Os dados trouxeram indícios de que o ensino ainda é centrado no professor e que os professores fazem pouca relação entre a Química, a Tecnologia e a Sociedade. Além disso, os pesquisadores tiveram a sensação de que os professores, ao ensinarem baseados no contexto, demonstravam menos controle interpessoal na sala de aula. Eles reconheceram que os professores foram desafiados a participar de uma experiência inovadora e que novas investigações devem ser realizadas.

O papel do professor na sala de aula está mudando, impulsionado principalmente pelo surgimento das tecnologias de informação e comunicação. De transmissor de informações organizadas, ele vem assumindo um papel mais amplo, o de facilitar a aprendizagem e auxiliar os estudantes a construírem significados para os conceitos científicos. Isso acontece mais facilmente quando os estudantes percebem os conceitos como necessários para entender os fenômenos do contexto. Para que professores sejam capazes de implementar um currículo ou um programa de ensino baseado no contexto, Coenders, Terlouw \& Dijkstra (2008) argumentam ser necessário o desenvolvimento de materiais de ensino e defendem que, sempre que possível, esses sejam produzidos pelos próprios professores.

Lupión-Cobos, López-Castilla e Blanco-López (2017) exploraram as visões e opiniões de quatro professores de Ciências do ensino secundário quando eles foram convidados a planejar, implementar e avaliar uma unidade didática baseada no contexto. A análise dos dados mostrou aspectos que os professores acreditam ser facilitadores nessa abordagem e, também, os que acreditam ser obstáculo. Para eles, a identidade profissional docente acaba por influenciar nas opções dos professores, de forma a provocar mudanças nas aulas que foram planejadas para serem baseadas no contexto.

Firme e Amaral (2011) acompanharam e analisaram as aulas de dois professores de Química, planejadas com enfoque CTS, com a intenção de identificar obstáculos e dificuldades para o estabelecimento de uma prática docente pautada nessa perspectiva de ensino. Segundo eles, as dificuldades estão associadas à ausência de informações técnicas e científicas sobre o tema; à complexidade científica na abordagem de alguns temas; à pouca experiência dos professores em articular adequadamente conceitos científicos com questões tecnológicas, associadas a um tema social relevante; e, ainda, à ausência de material didático que suporte as discussões de temas específicos na sala de aula.

Vos (2010) enfoca a implementação de materiais de ensino baseados em contexto pelos professores em suas práticas de sala de aula, e, especificamente, analisa se esses materiais são usados pelos professores de acordo com as intenções dos designers. Segundo ele, abordagens baseadas no contexto para o ensino de Ciências estão se tornando amplamente utilizadas no Ensino Médio. Tanto Vos (2010) quanto outros pesquisadores (ALTRICHTER, 2005; EILKS; RALLE, 2002; COENDERS; TERLOUW; DIJKSTRA, 2008) reconhecem ser necessário, além do material didático, o desenvolvimento profissional dos professores em termos de inovação educacional, desenvolvimento esse que admitem não ser simples de ser realizado.

Considerando as dificuldades que estudantes apresentavam quando o ensino era baseado no contexto, Wijaya, Van Den Heuvel-Panhuizen e Doorman (2015) investigaram a atuação de quatro professores da Indonésia que desenvolviam esse ensino e as crenças que possuíam. Por meio da análise dos dados, os pesquisadores afirmaram que os professores encorajavam os estudantes a se envolverem ativamente na 
resolução de problemas em vários contextos. Porém, revelaram que os professores viam as tarefas baseadas no contexto como problemas simples, e que o ensino era muito centrado no professor.

No presente trabalho, professores experientes foram colocados em contato com um material didático temático e com base nele desenvolveram aulas nas escolas em que atuavam. Tendo em vista que, no Brasil, é reduzido o número de publicações de materiais didáticos que organizam o conteúdo baseados em um tema do contexto, optamos por investigar aspectos relacionados a essa experiência, considerando o ponto de vista dos professores. Antes, porém, faz-se necessário explicitarmos a perspectiva do que consideramos contexto.

\subsection{Quando o contexto é considerado no ensino e as diferentes denominações}

Wartha, Silva e Bejarano (2013) fazem uma análise crítica do uso do termo "contextualização" em documentos curriculares oficiais, principalmente os Parâmetros Curriculares Nacionais. Apesar de o termo contextualização estar amplamente citado nesses documentos e, a partir deles, tenha passado a fazer parte dos discursos da comunidade científica, os autores argumentam que o seu significado possui origem anterior a eles. Após criteriosa análise, Wartha, Silva e Bejarano (2013, p. 90) ressaltam a polifonia do termo e indicam haver ao menos três perspectivas: a contextualização não redutiva, a partir do cotidiano; a contextualização a partir da abordagem CTS; e a contextualização a partir de aportes da história e da filosofia das Ciências.

Em nosso trabalho, o ensino baseado no contexto tem como perspectiva os pressupostos do movimento CTS. Olhamos para a literatura mais recente no sentido de identificar o termo usado pelos pesquisadores. Observamos que se referem ao ensino a partir de temas (por ex. FERREIRA et al., 2018; SWIECH, 2016), a temas sociocientíficos (por ex. MUNDIMI; SANTOS, 2012) ou mesmo a temas geradores como uma proposta de método de ensino (por ex. COSTA; PINHEIRO, 2013, MIRANDA; BRAIBANTE; PAZINATO, 2015). Porém, na literatura internacional mais vinculada ao movimento CTS (por ex. BENNETT; LUBBEN, 2006; WALAN; NILSSON; MC EWEN, 2017), a opção se dá pelo ensino baseado no contexto (contextbased).

Fazemos, ainda, uma breve apresentação dos textos referenciados acima como exemplo do que tem sido publicado em relação ao ensino por meio de temas, nas suas diferentes denominações. Swiech (2016) usou o tema camisinha como suporte para abordar diversos conteúdos de Química durante o ano letivo e a autora argumenta que esse uso representou um marco na formação do aluno que, junto com o professor, atuou e se envolveu em processos intermitentes de investigação e de discussão coletiva, o que gerou produção de conhecimentos. Ferreira et al., (2018), por sua vez, usam o tema "camisinha", associando ao entendimento desse tema algumas atividades experimentais envolvendo alguns processos oxidativos. Ao analisarem textos produzidos pelos estudantes ao final da sequência didática, os autores argumentam que houve apropriação de conceitos científicos e criticidade em relação ao uso dos corantes.

Mundimi e Santos (2012) desenvolveram o tema "Alimentação e vida saudável" em aulas do oitavo ano do Ensino Fundamental. Com essa experiência, os autores afirmam que houve maior interesse e participação dos estudantes durante as aulas e que isso foi acompanhado de uma maior compreensão do conteúdo científico. 
Miranda, Braibante e Pazinato (2015) fizeram uma investigação junto à comunidade escolar e, como resultado, elegeram o tema "drogas" como sendo o que despertou maior interesse e desenvolveram o que chamaram de situação de ensino a partir desse tema, nas disciplinas de Química e Biologia. Segundo as autoras, a utilização do tema gerador na estrutura do programa das disciplinas escolares favorece o ensino, bem como uma formação mais crítica e cidadã dos estudantes. Costa e Pinheiro (2013), a partir de um estudo teórico, afirmam que o emprego de temas geradores possibilita um ensino mais significativo, a promoção da interdisciplinaridade, o desenvolvimento da autonomia e do senso crítico do educando, além da aproximação entre professor e aluno (p. 37).

Bennett e Lubben (2006) analisaram um projeto desenvolvido na Inglaterra e no País de Gales, chamado Salters Advanced Chemistry, no qual o ensino de Química para estudantes do Ensino Médio foi baseado no contexto. Para eles, as evidências do impacto do curso, a partir das opiniões dos professores e das respostas afetivas e cognitivas dos alunos indicam que a experiência foi positiva para todos. Além disso, os estudantes desenvolveram níveis de entendimento de ideias químicas comparáveis aos presentes em cursos convencionais, o que significa que não houve qualquer prejuízo em termos de aprendizagem. Walan, Nilsson e Mc Ewen (2017), assim como em nosso trabalho, tiveram a água como contexto para ensinar.

Assim sendo, optamos pelo uso do termo "ensino baseado no contexto", por considerarmos que está mais vinculado aos pressupostos CTS e, também, por ser adequado a uma perspectiva que temos defendido já há algum tempo: o tema deve ser de interesse do estudante, para que esse se envolva na aula e tenha contribuições a oferecer para as discussões e, também, de interesse da Química, para que os conceitos científicos possam ser inseridos na discussão e na explicação dos fenômenos do contexto.

\section{METODOLOGIA}

Entre os professores que se utilizaram do material didático temático produzido, três deles eram experientes, ou seja, tinham mais de 10 anos de docência, ensinando Química. Esses três professores, de três escolas de Belo Horizonte, cidade localizada no estado de Minas Gerais/Brasil, receberam os cadernos temáticos que foram construídos usando a água como tema gerador, tratando dos seguintes subtemas: Ciclo da Água (QUADROS, 2016), Água na Natureza (QUADROS; SILVA, 2016) e Água e Plantas (QUADROS; SILVA; MARTINS, 2016). Além desse material impresso, também receberam um Kit contendo todo o material necessário para a realização dos experimentos presentes nas sequências didáticas. Foi informado aos professores, ainda, que os autores estariam à disposição para auxiliar no planejamento das aulas, sempre que os professores julgassem necessário. Não houve, portanto, uma formação específica para que os professores desenvolvessem as aulas a partir do material didático.

Os professores investigados usaram de 2 a 3 meses para desenvolver a sequência didática, sendo que um deles (Prof. 1) atuava na Educação de Jovens e Adultos (EJA) de uma escola particular, outro (Prof. 2) no Ensino Médio de uma escola particular, e o terceiro (Prof. 3) no EJA de uma escola pública. Ao todo foram cinco turmas de estudantes e três professores envolvidos. 
As aulas foram gravadas em vídeo para que pudéssemos, dessa forma, acompanhar o seu desenvolvimento. Os estudantes responderam a pré e pós testes para que pudéssemos analisar a apropriação de conceitos científicos e a capacidade de argumentação. Ao final da sequência didática, os professores foram entrevistados. Neste trabalho, analisamos as entrevistas dos três professores participantes, com o objetivo de avaliar a experiência desses professores ao desenvolverem aulas de Química a partir de um tema do contexto dos estudantes.

Optamos pelo uso da entrevista, tanto por se tratar de um número reduzido de sujeitos envolvidos quanto pela contribuição que essa técnica poderia oferecer para a coleta de dados espontâneos referentes ao discurso desses sujeitos. Ao desenvolverem aulas a partir de um tema do contexto social, fatores subjetivos estiveram envolvidos e a entrevista foi considerada um instrumento adequado para identificar alguns desses fatores. Valemo-nos de uma entrevista semiestruturada, ou seja, com questões que tratam de um tema sobre o qual o entrevistado discorre livremente, com interferências pontuais do entrevistador.

As entrevistas versaram sobre questões específicas envolvendo a sequência didática (motivação do professor, opinião sobre o material, resultados que considerava terem sido alcançados) e questões mais gerais (papel do estudante e do professor na sala de aula, por exemplo). Essas entrevistas, realizadas no local de trabalho do professor, foram gravadas em vídeo e transcritas na íntegra, para facilitar a análise. A partir da leitura inicial das entrevistas foram construídas quatro categorias de análise: $o$ compromisso principal demonstrado pelo professor ao ensinar Química, o papel do professor e dos estudantes nas aulas, a percepção do material didático e os resultados que perceberam junto aos estudantes. Para a análise, várias leituras foram realizadas, selecionando os trechos que se enquadravam nas categorias propostas a partir dos dados.

\section{RESULTADOS E DISCUSSÃO}

Nos relatos durante as entrevistas, os três professores afirmaram terem sido surpreendidos pelo interesse dos estudantes nas aulas, durante o desenvolvimento da sequência didática em questão. Porém, o entendimento do objetivo de uma sequência de aulas baseada no contexto foi diferente. A seguir apresentamos a análise feita levando em conta cada uma das categorias propostas a partir dos dados.

\subsection{Compromisso principal demonstrado pelo professor ao ensinar Química}

O material didático temático foi produzido ao longo de vários anos durante $o$ desenvolvimento de alguns de projetos. A sua publicação, no entanto, contou com o apoio de uma agência de fomento à pesquisa, de Minas Gerais. Em contrapartida, o material (versão do professor) foi distribuído às escolas gratuitamente, com um convite para que os professores fizessem uma parceria com a UFMG, recebendo o material para desenvolver a sequência didática com os estudantes e compartilhando os resultados com a equipe do projeto. Durante a entrevista foi perguntado aos três professores o motivo que os levou a optar pelo uso desse material em parceria com a UFMG. Selecionamos trechos da fala de cada um dos professores, que podem auxiliar a entender esse motivo e, com isso, o tipo de compromisso que o professor assumiu com os seus estudantes. No Quadro 1 transcrevemos o que disseram os professores. 
Quadro 1 - Falas dos professores referentes ao interesse no projeto.

\begin{tabular}{|c|c|c|}
\hline Prof. 1 & Prof. 2 & Prof. 3 \\
\hline $\begin{array}{l}\text { Quando eu comecei a dar aula } \\
\text { de Química, algumas vezes eu } \\
\text { pensava "gente por que eu tô } \\
\text { ensinando isso?". Então, eu } \\
\text { acho que a gente tem um } \\
\text { problema muito grande de } \\
\text { currículo na área da Química, } \\
\text { porque o aluno aprende coisas } \\
\text { que não consegue perceber } \\
\text { aplicação direta no cotidiano } \\
\text { dele. E desde essa época eu } \\
\text { tenho me preocupado com isso, } \\
\text { e o ensino a partir do contexto } \\
\text { pode, sim, potencializar a } \\
\text { compreensão dos alunos sobre o } \\
\text { mundo e fazer com que eles } \\
\text { sejam mais críticos e consigam } \\
\text { se posicionar de uma maneira } \\
\text { mais consciente na sociedade. } \\
\text { Eu busquei essa oportunidade } \\
\text { porque vinha ao encontro do } \\
\text { que eu já queria fazer. }\end{array}$ & $\begin{array}{l}\text { Olha, quando me apresentaram } \\
\text { os livros, eu folheei e eu gostei } \\
\text { deles. Depois eu olhei com mais } \\
\text { dedicação e vi que poderia ser } \\
\text { um bom material para trabalhar, } \\
\text { e pensei logo no terceiro ano, } \\
\text { por terem uma maturidade um } \\
\text { pouco melhor e, também, } \\
\text { porque poderia ser usado para } \\
\text { fazer uma revisão, e casar } \\
\text { aqueles conteúdos com o } \\
\text { ENEM. Muita coisa que estava } \\
\text { ali é conteúdo de ENEM, e da } \\
\text { maneira que o ENEM cobra. } \\
\text { Foi por isso que eu decidi usar o } \\
\text { livro. }\end{array}$ & $\begin{array}{l}\text { Eu comecei a dar aula sendo } \\
\text { bem conteudista, que é o que } \\
\text { tem nos livros e o que a gente } \\
\text { teve. Mas o estudante, que lida o } \\
\text { tempo todo com formulações, } \\
\text { que usa produtos, e que tudo que } \\
\text { o cerca está envolvido com } \\
\text { Química nem percebe isso. } \\
\text { Então eu quis mudar, mas é } \\
\text { difícil. Sendo professor, eu acho } \\
\text { que a gente tem que formar uma } \\
\text { sociedade um pouco mais crítica } \\
\text { e, durante o tempo que eu tenho } \\
\text { dado aula, eu tenho visto que } \\
\text { isso tem se perdido cada vez } \\
\text { mais. E eu estou aqui na sala de } \\
\text { aula, professora de Química, e } \\
\text { me pergunto: para que isso serve } \\
\text { pra minha vida? Pra vida do } \\
\text { aluno, né? Esse é o } \\
\text { questionamento que a gente tem } \\
\text { o tempo todo. } \\
\text { Então, participar poderia me } \\
\text { ajudar a entender isso. }\end{array}$ \\
\hline
\end{tabular}

Pelos dados constantes no Quadro 1 é possível perceber que as intenções dos professores, ao aderirem à proposta de parceria, não foram as mesmas. O Prof. 1 afirmou que já tinha o desejo de desenvolver a Química a partir do contexto dos estudantes e fazia algumas tentativas nesse sentido e, ao que parece, o material disponibilizado atendeu às suas expectativas. Ao que nos parece a Prof. 3 dedica atenção ao aspecto social, além de ter como meta o uso da Química para auxiliar no desenvolvimento cidadão de seus estudantes. Ao perceber que o ensino baseado no contexto poderia auxiliar os estudantes a entenderem o mundo que os cerca, ela optou por aderir ao convite recebido. A Prof. 2, no entanto, seguiu outro caminho. Ao que nos parece, a escola em que ela atua tem um compromisso maior com o Exame Nacional do Ensino Médio (ENEM), com a intenção forte de que seus estudantes cheguem ao ensino superior. Como esse exame (ENEM) usa questões que tratam do contexto, ela viu na proposta uma oportunidade de fortalecer o preparo dos estudantes para enfrentarem o ENEM.

Como já ressaltado, os professores investigados por Wijaya, Van Den HeuvelPanhuizen e Doorman (2015) tinham a concepção de que tarefas baseadas no contexto representavam problemas simples, desenvolvendo um ensino muito centrado no professor. A Prof. 2, que justificou o envolvimento com o ensino baseado no contexto como uma possibilidade de melhor preparar seus estudantes para o ENEM, também não citou o envolvimento ativo do estudante com as aulas. Ao que nos parece, as aulas que desenvolveu ainda eram muito centradas no professor.

O Prof. 1, no entanto, desenvolvia as aulas considerando o seu compromisso social e científico, enquanto a Prof. 3 parecia se sobressair no compromisso social. 
Trata-se, portanto, de entendimentos diferenciados dos objetivos do ensino baseado no contexto

\subsection{O papel do professor nas aulas}

O ensino pautado na transmissão de informações organizadas perdeu espaço com a multiplicação das fontes de informação, tais como livros, revistas, televisão e, principalmente, a rede mundial de informação e comunicação. Com isso, o papel do professor em sala de aula também foi mudando. De um ensino centrado totalmente no professor, chegamos a um tempo em que a tendência é tornar o estudante coprotagonista das aulas.

Uma das perguntas feitas aos professores diz respeito exatamente ao papel do professor em sala de aula. No Quadro 2 reproduzimos fragmentos da fala dos professores ao comentarem o papel do professor nas aulas de Química.

Quadro 2 - Fala dos professores referentes ao papel do professor em sala de aula.

\begin{tabular}{|c|c|c|}
\hline Prof. 1 & Prof. 2 & Prof. 3 \\
\hline $\begin{array}{l}\text { Eu estou bem convencido de que } \\
\text { quanto menos o momento de } \\
\text { ensino for centrado no professor, } \\
\text { mais rico é esse momento. Então } \\
\text { eu acho que o papel do professor } \\
\text { está muito mais no } \\
\text { planejamento. Eu acho que } \\
\text { durante a aula tem que ser uma } \\
\text { coisa mais autônoma para o } \\
\text { aluno e que o professor deve só } \\
\text { assegurar que as coisas estão } \\
\text { saindo como o planejado ou } \\
\text { fazendo relações, fechamentos } \\
\text { etc., chegando ao objetivo que } \\
\text { estava no planejamento. }\end{array}$ & $\begin{array}{l}\text { O professor? Ele tem que ser } \\
\text { capaz de despertar a atenção } \\
\text { dos meninos, o interesse, e } \\
\text { fazer com que eles debatam, } \\
\text { participem, façam a construção } \\
\text { do conceito, e não apenas } \\
\text { decorem. Eles têm que saber } \\
\text { construir o conceito a partir de } \\
\text { alguma vivência deles e tentar } \\
\text { explicar isso. }\end{array}$ & $\begin{array}{l}\text { Antigamente existia uma visão de } \\
\text { professor como transmissor de } \\
\text { conteúdos básicos. Esse era o } \\
\text { papel fundamental do professor } \\
\text { há um tempo. Hoje não! Hoje o } \\
\text { professor já não é mais aquele que } \\
\text { é o detentor do conhecimento que } \\
\text { vai repassar para as outras } \\
\text { pessoas, para aqueles alunos, } \\
\text { aqueles participantes ali daquela } \\
\text { comunidade que é a sala de aula. } \\
\text { Hoje, nós, professores, ocupamos } \\
\text { um espaço talvez até bem inferior } \\
\text { a aquilo que a gente tinha. Mas } \\
\text { por outro lado esse espaço é bem } \\
\text { superior também, porque nós } \\
\text { podemos ser mediadores e ensinar } \\
\text { esses jovens a pensar e a entender } \\
\text { o mundo. }\end{array}$ \\
\hline
\end{tabular}

A ideia de tornar o estudante coprotagonista das aulas constou das falas dos Prof. 1 e Prof. 3. O primeiro destacou a importância de planejar e de ter objetivos bem definidos, ou seja, de saber "onde" se quer chegar ao desenvolver certo conteúdo, enquanto a Prof. 3 falou de ocupar, provavelmente com sua fala, um tempo inferior ao que ocupava no passado, citando, inclusive, o papel de mediação exercido pelo professor na sala de aula, ao trabalhar com temas do contexto social. Esses dados vêm ao encontro do que foi descrito por Walan e Mc Ewen (2017), cuja pesquisa mostrou que os professores melhoraram o entendimento em relação a estratégias que tornassem o estudante mais ativo e o ensino menos centrado no professor.

A Prof. 2 referiu-se ao professor mais como motivador, para assim promover o envolvimento dos estudantes com as aulas. Ao não oferecer evidências de como essa motivação aconteceria, a professora parece esperar do estudante uma postura mais ativa, sem desenvolver estratégias para que isso aconteça. Uma melhor análise do papel dos estudantes como coprotagonistas será realizada no próximo tópico. 


\subsection{O papel dos estudantes nas aulas}

Como já dissemos, o conhecimento centrado no professor é uma ideia que não encontra mais espaço diante das tecnologias de informação e comunicação. Nesse sentido, o estudante tem sido considerado protagonista na aula e corresponsável pelo seu próprio processo de aprendizagem. Como não poderia deixar de ser, estamos em um processo de transição, ou seja, em processo de mudança, pois o modelo de ensino que costumamos chamar de tradicional faz parte da nossa cultura, mas com tendência de que seja transposto ou não tenha mais espaço na sociedade cada vez mais tecnológica.

Ao perguntarmos aos professores acerca do papel do estudante em sala de aula, notamos que os comentários vieram consolidar o que já tinha sido tratado no item "4.2", pois o papel do estudante depende do papel assumido pelo professor. O Quadro 3 dá uma ideia desses comentários.

Quadro 3 - Fala dos professores referentes ao papel do estudante em sala de aula.

\begin{tabular}{|c|c|c|}
\hline Prof. 1 & Prof. 2 & Prof. 3 \\
\hline $\begin{array}{l}\text { O estudante só vai se interessar } \\
\text { se ele perceber que aquilo, de } \\
\text { alguma maneira, será } \\
\text { importante pra ele. Então, é } \\
\text { altamente indicado tratar de } \\
\text { temas, que de alguma maneira } \\
\text { são presentes no dia a dia dos } \\
\text { alunos, para que eles consigam } \\
\text { vislumbrar e ver que aquilo tem } \\
\text { alguma relevância. }\end{array}$ & $\begin{array}{l}\text { Ser mais participativo, ele tem } \\
\text { que ter mais interesse, coisa que } \\
\text { tá difícil de acontecer na atual } \\
\text { conjuntura. Eles não querem } \\
\text { muito saber de estudos, não. } \\
\text { Eles querem só fazer o que eles } \\
\text { gostam, e o negócio deles é } \\
\text { muito a parte digital, o que é } \\
\text { digital eles se interessam um } \\
\text { pouco mais. Mas tem que ter a } \\
\text { participação deles, e isso não } \\
\text { está acontecendo. }\end{array}$ & $\begin{array}{l}\text { Nós somos adultos, temos } \\
\text { família, temos tantas coisas, que } \\
\text { muitas vezes a gente não } \\
\text { consegue acompanhar com a } \\
\text { mesma disponibilidade que eles } \\
\text { têm, ou seja, tudo que acontece. } \\
\text { Então, muitas vezes, são eles que } \\
\text { nos trazem a problemática, né?. } \\
\text { O aluno de hoje, ele não vai, } \\
\text { simplesmente, ficar ali na sala de } \\
\text { aula, como um vasinho, um vaso } \\
\text { de planta ou uma jarra, onde } \\
\text { você só vai enchendo. Não existe } \\
\text { mais esse perfil de aluno! }\end{array}$ \\
\hline
\end{tabular}

A Prof. 3 demonstrou conhecimento dos interesses e das necessidades dos estudantes. Em geral são jovens que demonstram grande capacidade de engajamento em situações que lhes são atrativas: banda favorita, jogos eletrônicos, redes sociais etc. Talvez essa percepção tenha levado a professora a afirmar que esses jovens são tão dinâmicos que não se adaptam a uma postura passiva em sala de aula. E como ela afirmou, o estudante sentado, quieto, apenas prestando atenção no que o professor fala, não existe mais. Com isso, entendemos que, na opinião dela, o estudante deve ter uma postura mais ativa e isso depende de estratégias que o professor usa. A Prof. 2 trouxe a ideia de um estudante mais participativo e interessado, mas a sua fala nos dá a sensação de que isso é o que ela espera do estudante, independentemente do tipo de aula que realize. Inúmeros trabalhos (VOS, 2010; OVERMAN et al., 2014; ALTRICHTER, 2005) têm mostrado que o interesse e a participação dos estudantes em aulas de Ciências aumentam significativamente quando o foco é o entendimento de um tema do contexto.

O Prof. 1, por sua vez, também falou do interesse do estudante, mas enfatizou que isso depende do tipo de aula, citando o ensino baseado no contexto como uma possibilidade efetiva de desenvolver esse interesse. Assim como relatado no trabalho de Walan e Mc Ewen (2017), no qual os professores participaram de um programa de 
formação continuada, o Prof. 1 nos dá a ideia de que o ensino baseado no contexto o levou a desenvolver estratégias adequadas para a participação dos estudantes.

\subsection{O material didático em questão}

Por se tratar de um material didático, desenvolvido a partir do tema água, cuja forma de apresentação do conteúdo difere da maior parte dos livros didáticos disponíveis no mercado, perguntamos a esses professores a percepção que tiveram ao usar o material, em termos de qualidade e de potencial para a produção de aprendizagens. No Quadro 4 transcrevemos trechos das respostas dos professores a essa questão.

Quadro 4 - Fala dos professores sobre o material didático

\begin{tabular}{|c|c|c|}
\hline Prof. 1 & Prof. 2 & Prof. 3 \\
\hline $\begin{array}{l}\text { Ele trata de um tema que tem } \\
\text { relevância social e que tem } \\
\text { relação com a tecnologia. Eu já } \\
\text { fazia então coisas diferentes } \\
\text { com os estudantes, mas eu era o } \\
\text { protagonista das aulas, sempre, } \\
\text { ou quase sempre. Eu tinha que } \\
\text { ficar o tempo inteiro dando } \\
\text { informação e tal. Eu acho que a } \\
\text { partir do livro, as atividades que } \\
\text { são propostas são para que os } \\
\text { alunos sejam protagonistas e } \\
\text { deem conta de fazer isso, né?. } \\
\text { Então eu passei a dar menos } \\
\text { "aulas", né?. Ela acontecia pelos } \\
\text { alunos mesmo, eu só estava ali } \\
\text { como um orientador deles. É } \\
\text { claro que em alguns momentos } \\
\text { tinham as discussões mais } \\
\text { teóricas e aí eu assumia a } \\
\text { explicação. Mas de uma } \\
\text { maneira geral os alunos faziam } \\
\text { as coisas. }\end{array}$ & $\begin{array}{l}\text { Olha, eu achei muito } \\
\text { interessante os módulos. } \\
\text { Percebi que os meninos } \\
\text { interagiam bastante, porque } \\
\text { exatamente lá foi apresentado } \\
\text { um conceito, não de forma para } \\
\text { eles decorarem, eles foram } \\
\text { construindo o conceito a partir } \\
\text { das experiências. Ali tinha } \\
\text { conceitos básicos, nada } \\
\text { aprofundado, não um conteúdo } \\
\text { aprofundado, mas o básico que } \\
\text { eles necessitam. Quando você } \\
\text { dá um material diferente do que } \\
\text { eles estão acostumados, eles } \\
\text { têm um interesse diferente, } \\
\text { porque fugiu daquela coisa } \\
\text { tradicional. Então, quando foge } \\
\text { do tradicional, eles se envolvem } \\
\text { mais. Então foi nota dez. }\end{array}$ & $\begin{array}{l}\text { Eu gosto de novidade. De certa } \\
\text { forma eu já pensava em fazer } \\
\text { algo assim, com essa roupagem } \\
\text { bem diferente, mas é difícil. Já } \\
\text { esse material estava } \\
\text { organizadinho, com conceitos } \\
\text { relacionados entre si, com muita } \\
\text { novidade. Parece que é aquilo } \\
\text { que eu queria. Usou assuntos } \\
\text { que são relevantes, que é legal } \\
\text { que eles compreendam, né? } \\
\text { Aquela discussão sobre o leite, } \\
\text { eu achei superpertinente de } \\
\text { fazer, eu até levei pra uma outra } \\
\text { turma. Achei muito interessante } \\
\text { a maneira como foi abordada a } \\
\text { tensão superficial, as forças } \\
\text { intermoleculares, né?. Enfim, eu } \\
\text { achei bem interessante. }\end{array}$ \\
\hline
\end{tabular}

No que se refere ao Prof. 1, podemos perceber que a experiência com o material didático auxiliou na percepção do papel do professor em sala de aula, e que uma organização de atividades voltadas para os estudantes e para a discussão de ideias no espaço da sala de aula foi importante para ele. Em relação a ser um material temático, ele nos dá a entender que já tentava trabalhar nessa linha. Portanto, o material didático veio ao encontro de uma concepção de ensino que já possuía.

A Prof. 2 falou da forma como os conceitos foram introduzidos e do envolvimento dos estudantes, principalmente por representar um diferencial em relação às aulas que ela desenvolvia. Porém, ao falar de "conceitos básicos", sem profundidade, ela pode estar fazendo uma crítica ao material. Sabemos que quando o objetivo é o preparo do estudante para um processo seletivo, geralmente se trabalha uma grande quantidade de conteúdo e com mais profundidade. Porém, nesse caso, o contexto não costuma ser explorado. Como a ênfase do material é o entendimento do contexto e os 
conceitos são explorados para auxiliar nesse entendimento, é possível que ela tenha estranhado o que chamou de "nada aprofundado".

A Prof. 3 afirmou, assim como o Prof. 1, que já tinha a ideia de desenvolver as aulas a partir do contexto. Porém, nos pareceu que ela tinha dificuldade em organizar uma sequência de aulas baseada no contexto. Nessa experiência, ela desenvolveu um tema no qual muitos conceitos foram explorados, o que a levou a elogiar o material.

Não temos dúvida de que esses três professores, mesmo sendo experientes, não se julgavam aptos a modificar o ensino que faziam, passando a centrá-lo no contexto, mesmo tendo isso como objetivo (Prof. 1 e Prof. 3). Essa experiência pode ter contribuído para que se sintam encorajados a se tornarem autores de suas próprias aulas ou, como defendem Coenders, Terlouw \& Dijkstra (2008), que produzam seus próprios materiais didáticos.

\subsection{Os resultados obtidos junto aos estudantes}

Rodrigues (2016), ao fazer revisão da literatura no que se refere à relação entre o letramento científico e a aprendizagem, afirma que há uma corrente indicando que a abordagem CTS potencializa a aprendizagem de conceitos científicos e outra que, apesar de reconhecer vantagens na abordagem CTS, considera que ela não propicia a maior apropriação de conceitos científicos do que a abordagem tradicional. Como esses professores não fizeram uma investigação acerca da aprendizagem, perguntamos a eles qual a percepção que tiveram em relação aos resultados junto aos estudantes. O Quadro 5 apresenta parte das respostas obtidas.

Quadro 5 - Percepção dos professores quanto aos resultados junto aos estudantes.

\begin{tabular}{|c|c|c|}
\hline Prof. 1 & Prof. 2 & Prof. 3 \\
\hline $\begin{array}{l}\text { Eles já eram participativos. Mas } \\
\text { eram sempre os mesmos que } \\
\text { participavam, eu percebia que tinha } \\
\text { muita gente que ficava sem falar. E } \\
\text { aí eles ficaram tão empolgados com } \\
\text { a construção do terrário, pra ver o } \\
\text { que ia acontecer, se a planta ia } \\
\text { continuar viva, se a planta ia } \\
\text { morrer. Isso engajou muito eles, foi } \\
\text { quase uma "doideira". Então, os } \\
\text { que participavam continuaram } \\
\text { participando e os que não } \\
\text { participavam começaram a } \\
\text { participar bastante das aulas. E tem } \\
\text { o resultado nas avaliações escritas, } \\
\text { que eles foram bem melhores que } \\
\text { nas etapas anteriores. Acho que foi } \\
\text { um ganho bem interessante pra eles, } \\
\text { não só na parte científica, mas } \\
\text { também na parte de formação } \\
\text { pessoal. E essa experiência de } \\
\text { trabalhar com um material temático } \\
\text { mexeu muito comigo, no sentido de } \\
\text { mostrar que dá pra fazer diferente. }\end{array}$ & $\begin{array}{l}\text { Algumas atividades que eu } \\
\text { realizei eram opcionais. } \\
\text { Por exemplo, o debate. } \\
\text { Eles não eram obrigados a } \\
\text { participar. E a participação } \\
\text { foi quase } 100 \% \text {. Em uma } \\
\text { turma } 100 \% \text {, na outra só } \\
\text { um aluno não quis } \\
\text { participar. Então ele foi } \\
\text { avaliado de maneira } \\
\text { diferente, já que não } \\
\text { participou. Então acho que } \\
\text { foi extremamente positivo, } \\
\text { e construtivo isso, tanto } \\
\text { pra mim quanto pra eles. }\end{array}$ & $\begin{array}{l}\text { A maneira como eles se portavam } \\
\text { dentro da sala de aula já indicava } \\
\text { que era uma turma boa. Mas a } \\
\text { EJA tem um perfil de alunos que } \\
\text { trabalham o dia todo e que tem } \\
\text { dificuldade com os conceitos } \\
\text { científicos. Mas olha só: eu } \\
\text { apliquei para eles a mesma prova } \\
\text { da turma regular (não EJA) e eles } \\
\text { conseguiram se sair muito } \\
\text { melhores do que os alunos do } \\
\text { regular. E o interesse deles, } \\
\text { então! As aulas eram na sexta- } \\
\text { feira à noite, e geralmente a } \\
\text { escola fica vazia. E até meus } \\
\text { colegas comentavam "você está } \\
\text { trazendo esses meninos tudo aqui } \\
\text { na sexta-feira". E eles vinham pra } \\
\text { ter aula, né?, porque eles } \\
\text { gostavam da aula, né? Eles } \\
\text { participavam, perguntavam, né?, } \\
\text { então eu percebi que eles } \\
\text { gostaram muito da maneira como } \\
\text { as aulas estavam organizadas. }\end{array}$ \\
\hline
\end{tabular}


Os três professores destacaram o interesse dos estudantes e a participação intensa nas atividades realizadas. A Prof. 3 ressaltou que a turma em que se deu essa experiência tinha aulas na sexta-feira à noite, turno que os estudantes não costumam frequentar. Porém, segundo ela, todas as aulas aconteceram porque os estudantes estavam empolgados com a sequência didática e, por isso, compareceram às aulas. Sabemos que, quando o foco se dá em um tema que o estudante conhece, ele oferece contribuições que auxiliam na dinâmica da aula. Além disso, ao perceber a direta relação dos conceitos com a situação discutida em aula, o estudante geralmente se mostra mais interessado. É esperado que esse interesse e participação tenham como resultado uma melhor aprendizagem, embora isso não tenha sido, até então, objeto de investigação na turma em que a Prof. 3 atuou.

O Prof. 1 comentou a evolução na participação dos estudantes que antes eram menos participativos e que nessa sequência de aulas passaram a participar ativamente. A Prof. 2 também trouxe o caso de um debate que realizou, para o qual a participação era voluntária, destacando que apenas um estudante, de uma das turmas, não participou. Portanto, em termos de participação e de interesse dos estudantes pelas aulas, os professores afirmaram que a experiência foi bastante positiva. Esses dados vêm ao encontro das pesquisas destacadas por Rodrigues e Quadros (2019) que afirmam ser o ensino baseado no contexto um potencializador da aprendizagem de conceitos científicos

Pudemos perceber que, do ponto de vista do professor, foi uma experiência inovadora. Apesar de terem demonstrado um compromisso formativo diferente, esses três professores valorizaram o material didático utilizado como apoio às aulas e enfatizaram os resultados positivos dessa experiência junto aos estudantes.

\section{CONSIDERAÇÕES FINAIS}

Pesquisas têm sido realizadas envolvendo o uso de material didático baseado no contexto (VOS, 2010; OVERMAN et al., 2014) e o uso que os professores fazem dele. No trabalho que realizamos, o material didático se mostrou importante para que esses professores desenvolvessem aulas em que o contexto fosse explorado. No entanto, a inserção em um "outro modo" de dar aulas depende de fatores subjetivos: as crenças do professor sobre o ensino, por exemplo, acabam por interferir na sua prática, o que acreditamos tenha acontecido com a Prof. 2. Nesse sentido, se quisermos a inserção de um ensino baseado no contexto nas escolas brasileiras, é preciso um investimento no desenvolvimento profissional dos professores, associado à produção de material didático que possa auxiliar na organização/planejamento das aulas.

Baseados na análise dos dados, argumentamos, assim como o fizeram Coenders, Terlouw \& Dijkstra (2008) e Firme e Amaral (2011), pela necessidade de que material didático temático seja produzido e disponibilizado aos professores e às escolas, servindo de suporte para o desenvolvimento de aulas baseadas no contexto. $\mathrm{O}$ ensino baseado no contexto é uma proposta que, apesar de fazer parte das discussões do campo do Ensino de Ciências, poucas vezes tem sido efetivamente implantada nas salas de aula. $\mathrm{O}$ material didático auxiliou os professores a construir suas próprias aulas a partir de um tema. Esse dado traz implicações importantes para o campo de Ensino de Ciências. Se temos pouco material didático que auxilie os professores a construir aulas cujo foco seja o entendimento de um tema do contexto social, quem poderá produzi-los? Nossa 
experiência tem mostrado que uma parceria entre pesquisadores (das universidades) e professores em serviço (da Educação Básica) pode trazer bons resultados em termos de produção didática e, por isso, assim como o fazem Coenders, Terlouw e Dijkstra (2008), consideramos esse um caminho promissor para a elaboração de materiais didáticos.

Este trabalho investigou três professores, o que representa um número bastante limitado. Como base em nossa experiência, acreditamos, no entanto, que se estendermos os resultados aqui apresentados a um número maior de professores, podemos inferir que é possível praticar um ensino de Ciências que envolva os estudantes com essa Ciência e que traga mais satisfação aos professores.

\section{REFERÊNCIAS}

ALTRICHTER, H. Curriculum implementation - limiting and facilitating factors. In P. Nentwig \& D. Waddington (Eds.), Making it relevant. Munich: Waxmann, 2005, p. 121-153.

BENNETT, J.; LUBBEN, F. Context-based Chemistry: The Salters approach. International Journal of Science Education, v. 28, n. 9, p. 999-1015, 2006.

BROMAN, K.; BERNHOLT, S.; PARCHMANN, I. Analysing task design and students' responses to context-based problems through different analytical frameworks. Research in Science \& Technological Education, v. 33, n. 2, p. 143-161, 2015.

COENDERS, F.; TERLOUW, C.; DIJKSTRA, S. Assessing teachers' beliefs to facilitate the transition to a new chemistry curriculum: What do the teachers want? Journal of Science Teacher Education, v. 19, p. 317-335, 2008.

COSTA, J. M.; PINHEIRO, N. A. M. Educação pensada de forma contextualizada, problematizada e interdisciplinar. Imagens da Educação, v. 3, n. 2, p. 37-44, 2013.

DE JONG, O. Context-based chemical education: How to improve it?. Chemical Education International, v.8, n. 1, p. 1-7, 2008.

EILKS I.; RALLE B. Participatory action research in chemical education. In: B. Ralle and I. Eilks (Eds.), Research in chemical education -- what does it mean? Aachen, Germany: Shaker, 2002, p. 87-98.

FERREIRA, W. M.; ROCHA, L. B.; SANTOS, L. D.; SANTOS, B. L. S. R.; PITANGA, A. F. Corantes: Uma Abordagem com Enfoque Ciência, Tecnologia e Sociedade (CTS) usando Processos Oxidativos Avançados. Química Nova na Escola, v. 40, n. 4, p. 249-257, 2018.

FIRME, R. N.; AMARAL, E. M. R. Analisando a implementação de uma abordagem CTS na sala de aula de Química. Ciência \& Educação, v.17, n. 2, p. 383-399, 2011.

KING, D. T.; RITCHIE, S. M. Academic Success in Context-Based Chemistry: Demonstrating fluid transitions between concepts and context. International Journal of Science Education, v. 35, n. 7, p. 1159-1182, 2013.

LUPIÓN-COBOS, T.; LÓPEZ-CASTILLA, R.; BLANCO-LÓPES, Á. What Do Science Teachers Think about Developing Scientific Competences through ContextBased Teaching? A Case Study. International Journal of Science Education, v. 39, n.7, p. 937-963, 2017. 
MIRANDA, A. C. G.; BRAIBANTE, M. E. F.; PAZINATO, M. S. Tema gerador como estratégia metodológica para a construção do conhecimento em Química e Física. Experiências em Ensino de Ciências, v.10, n. 1, p. 98-113, 2015.

MUNDIMI, J. V.; SANTOS, W. L. P. Ensino de ciências no ensino fundamental por meio de temas sociocientíficos: análise de uma prática pedagógica com vista à superação do ensino disciplinar. Ciência \& Educação, v. 18, n. 4, p. 787-802, 2012.

NIEZER, T. M.; SILVEIRA, R. M. C. F.; SAUER, E. Ensino de soluções químicas por meio do enfoque Ciência-Tecnologia-Sociedade. Revista Electrónica de Enseñanza de las Ciencias, v. 15, n. 3, p. 428-449, 2016.

OVERMAN, M.; VERMUNT, J.; MEIJER, P.; BULTE, A.; BREKELMANS, M. Students' Perceptions of Teaching in Context-Based and Traditional Chemistry Classrooms: Comparing Content, Learning Activities, and Interpersonal Perspectives. Research in Science Education, v. 36, n. 11, p. 1871-1901, 2014.

QUADROS, A. L. Entendendo o Ciclo da Água (Coleção Temas de Estudo em Química). 1. ed. Contagem - MG: Didática Editora do Brasil Ltda., 2016.

QUADROS, A. L.; SILVA, G. F. A água na Natureza (Coleção Temas de Estudo em Química). 1. ed. Contagem - MG: Didática Editora do Brasil Ltda., 2016.

QUADROS, A. L.; SILVA, G. F.; MARTINS, D. C. S. (2016). As plantas e o Ciclo dos Elementos (Coleção Temas de Estudo em Química). 1. ed. Belo Horizonte: Didática Editora do Brasil Ltda., 2016.

RODRIGUES, V. B.; QUADROS, A. L. Contribuições do Ensino de Química na Perspectiva CTS para a Aprendizagem de Conceitos Científicos. Revista Debates em Ensino de Química, v. 5, n. 1, p. 45-53, 2019.

SWIECH, J. N. D. A camisinha como artefato tecnológico no ensino de Química, Química Nova na Escola, v. 38, n. 3, p. 230-236, 2016.

ULUSOY, F. M.; ONEN, A. S. A. Research on the Generative Learning Model Supported by Context-Based Learning. Eurasia. Journal of Mathematics, Science \& Technology Education, v. 10, n. 6, p. 537-546, 2014.

UMMELS, M. H. J.; KAMP, M. J. A.; KROON, H.; BOERSMA, K. T. Promoting Conceptual Coherence Within Context-Based Biology Education. Science Education, v. 99, n. 5, p. 958-985, 2015.

VOS, M. A. J. Interaction between teachers and teaching materials: on the implementation of contextbased chemistry education. Eindhoven: Technische Universiteit Eindhoven, 2010. DOI: 10.6100/IR684861

WALAN, S.; MC EWEN, B. Primary Teachers' Reflections on Inquiry- and ContextBased Science Education. Research in Science Education, v. 47, n. 2 p. 407-426, 2017.

WALAN, S.; NILSSON, P.; MC EWEN, B. Why Inquiry? Primary Teachers' Objectives in Choosing Inquiry- and Context-Based Instructional Strategies to Stimulate Students' Science Learning. Research in Science Education, v. 47, n. 5, p. 1055-1074, 2017.

WALAN, S; MC EWEN, B.; GERICKE, N. Enhancing Primary Science: An Exploration of Teachers' Own Ideas of Solutions to Challenges in Inquiry- and ContextBased Teaching. Research in Education, v. 44, n. 1, p. 81-92, 2016. 
WARTHA, E. J.; SILVA, E. L.; BEJARANO, N. R. R. Cotidiano e Contextualização no Ensino de Química. Química Nova na Escola, v. 35, n. 2, p. 84-91, 2013.

WIJAYA, A.; VAN DEN HEUVEL-PANHUIZEN, M.; DOORMAN, M. Teachers' Teaching Practices and Beliefs Regarding Context-Based Tasks and Their Relation with Students' Difficulties in Solving These Tasks. Mathematics Education Research Journal, v. 27, n. 4, p. 637-662, 2015. 